\title{
Invoking Learned Intermediary Rule in Malaysia
}

\author{
Fahirah Syaliza Mokhtar \\ PhD Candidate, Faculty of Law, Universiti Kebangsaan Malaysia, 43600, Bangi, Selangor, Malaysia \\ syalizamnco@gmail.com
}

\section{Rahmah Ismail}

Associate Professor, Faculty of Law, Universiti Kebangsaan Malaysia, 43600, Bangi, Selangor, Malaysia irahmah@ukm.edu.my

\section{Anisah Che Ngah}

Associate Professor, Faculty of Law, Universiti Kebangsaan Malaysia, 43600, Bangi, Selangor, Malaysia

Doi:10.5901/mjss.2015.v6n2p428

anisah@ukm.edu.my

\section{Abstract}

In the realm of pharmaceutical liability, failure to warn or to provide sufficient information such as adverse reaction or allergies of pharmaceutical products may cause manufacturers to be liable under the traditional common law of tort for the harm or death it causes. This article shows that manufacturers of prescribed pharmaceutical products may escape such liability if information and warnings have been conveyed to physicians; a learned intermediary between the manufacturers and the patients. The learned intermediary rule acts as a defence mechanism for manufacturers of pharmaceutical products as the physician is deemed as an intervening force that breaks the chain of causation in the law of negligence. Hence, the main focus of this article is to examine whether Malaysian courts would accept such a defence if invoked by the manufacturers. The objective of the article is to analyze and identify the learned intermediary between the manufacturer of a prescribed pharmaceutical products and patients under the relevant Malaysian statutes, particularly Poison Act 1952 and Medicines (Advertisement and Sale) Act 1956. In achieving the above objective, the authors adopts historical, comparison and also critical analysis methods. The finding of this article is that, it is an offence for pharmaceutical products to be sold or supplied directly to patients and strictly requires a learned intermediary such as physician to prescribe such products. Thus, it is concluded that the defence has its merits and therefore it is unlikely patients would be able to obtain compensation if this defence is invoked.

Keywords: medical product liability, pharmaceutical device, learned intermediary rule, duty to warn

\section{Introduction}

Calabro (2004) reported that alarmingly 200,000 Americans have died due to side effects or adverse reactions to prescribed medicine. Furthermore, an astounding 2.1 million injuries occur annually due to the same cause in studies conducted by the United States Center for Drug Safety. It is difficult to assess the situation in Malaysia as studies conducted by Isa NM et al (2013) reported that only 2000 adverse reactions were reported over the last 10 years due to lack of information on how to report an adverse drug reaction (ADR). The consequence that entails this situation is disturbing as this may reflect that many more ADRs have gone unreported, hence no action has been taken to prevent the medicine from continuously being prescribed to patients and the responsible manufacturer has yet to be brought to justice.

The general rule of liability due to failure to warn under the traditional law of tort is that the manufacturer would be liable to compensate the consumer if the manufacturer knew or should have known the risks based on scientific and technical knowledge of the product produced (Grubb, 2002). The principle was laid down in the case of Graham's Barclays Oysters Pty Ltd v Ryan ([2002] 211 CLR 540, 585) where the court decided:

"[a] manufacturer's duty includes responsibility for ensuring that appropriate and necessary information about the product is communicated to persons who will use or consume the product, and who it can be foreseen may suffer loss or damage."

In the context of medical products (pharmaceutical and medical devices) Casey (1993) and the decision of Phelps $v$ Sherwood Medical Industries (836 F. 2d 296 97 ${ }^{\text {th }}$ Cir. 1987) have shown that it is the duty of the manufacturers of medical products to keep abreast of the latest scientific developments and alert the patients of the risks, either by 
withdrawing those products from the market or making a public statement so that the warning comes to the knowledge of the patient if they discover the defects. In Vacwell Engineering v BDH Chemical ([1971] 1 QB 88) the court imposed liability on the defendant's failure to give adequate warning to the plaintiff as the defendant had failed to warn the plaintiff that boron tribromide is a type of explosive substance in which the information had been published in scientific journals. Marshall (2001) highlights that if prescription drugs contain risks that cannot be avoided (unavoidable risks) then they must have adequate warning labeling. The lack of warning or information, according to his study, is a legitimate defect in law which patients may take action upon. Extra warning is vital when it involves dangerous substances such as held in Ward v. Hopkins ([1959] 3 All ER 225):

The man who concocts a deadly poison and leaves it in a bottle to which other people have access does not adequately comply with his duty to warn of the danger merely by affixing a label 'Not to be taken'. A clear warning that the bottle contains poison would in such circumstances be imperatively required.

However, it is increasingly difficult to ignore the fact that manufacturers may escape liability if patients suffer injury or death due to adverse reaction to the medical product used. Calabro (2004) explains that the normal course of action for non-pharmaceutical products is usually taken against the manufacturer; nevertheless, it is not the case when it involves prescription medical products. The manufacturer shields itself behind the cloak of learned intermediary rule in which Calabro (2004) maintains that the manufacturer 'fulfills its legal duty to warn by merely providing an accurate and adequate warning to the prescribing physician.'The result of this study shows that if a patient suffers injury or death due to failure to warn of risks or potential adverse reaction to all prescription drugs (Taurino v Ellen 579 A $2 d 925(\mathrm{~Pa}$. Super.Ct.1990)), the patients claim against the manufacturer is likely to fail when learned intermediary rule (LIR) is invoked.

Therefore, it is the aim of this article to examine whether there is a possibility that the courts in Malaysia would accept such defence as has been exemplified by England, Canada and Australia in actions taken against manufacturers for injury and death due to failure to warn. The significance of this article above would indicate further studies should be conducted on how to assist patients in claiming compensation when such defence can be invoked by the manufacturer. It is unfair for patients to bear the financial burden due to warning and labelling defects of pharmaceutical products and failure to warn by both manufacturer and physicians respectively. By adopting the historical method, this article will start by explaining the meaning of LIR, historical background, justification and exceptions of the LIR. This method would offer a firm understanding of why such defense exists before approaching the scenario of LIR in Malaysia. In achieving the objective of this article, it is pertinent to first understand the distribution process of pharmaceutical product to patients by critical analyzing the Poison Act 1952 as the provisions of selling and supplying prescribed pharmaceutical products are governed under this Act. It is then followed by the study of the advertisement of pharmaceutical products under Medicines (Advertisement and Sale) Act 1956 in which the Act prohibits any form of advertising of drugs relating to certain disease. This critical analysis method of these statutes are adopted to identify the learned intermediary in the distribution process.

\section{The Learned Intermediary Rule}

Large volumes of literature have been published describing the role of LIR in the United States, which is only logical as it is the birthplace of the defense. It has been reported frequently in case laws that the idea of LIR was introduced in 1948 in the case of Marcus v Specific Pharmaceutical (77 N.Y.S 2d 508). In this case, Marcus took action against the pharmaceutical company for the death of his 13 month-old son who had overdosed due to lack of adequate usage recommendation, where the manufacturer had failed to mention the dosage requirement for children. The court had rejected Marcus's claim against the manufacturer as the court found that the manufacturer had made representation and had adequately warned the physician, an intermediary between the manufacturer and Marcus.

The case of Sterling Drug v Cornish ([1966] 370 F.2d 82) was the first case that coined the term 'Learned Intermediary'. In this case, the patient was suffering from adverse reaction to prescribed medicine and demanded compensation from the pharmaceutical manufacturer due to failure to warn about the side effects. The Court of Appeal stated:

In this case we are dealing with a prescription drug rather than a normal consumer item. In such a case the purchaser's doctor is a learned intermediary between the purchaser and the manufacturer. If the doctor is properly warned of the possibility of a side effect in some patients, and is advised of the symptoms normally accompanying the side effect, there is an excellent chance that injury to the patient can be avoided.

History has shown that the defense has been widely used in the United States until today. Casey (1993) claimed that the doctrine of LIR emerged as an accepted tort principle that has been invoked either directly or indirectly in nearly 
every case where a plaintiff brought a warning-related action against a prescription drug manufacturer. Study by Casey's (1993) was quite accurate as can be seen in the recent case of Roseanne Sanchez et al v Boston Scientific Corporation (2014 U.S Dist. LEXIS 114122), where the patient sued the manufacturer (BSC) for failing to warn about particular risks related to their medical device. The patient contended that BSC could not seek refuge under the LIR as the manufacturer failed to adequately warn the physician of the risks. The court held that the patient was erroneous as the plaintiff must prove that BSC's warning was inadequate, and that the inadequacy was the substantial factor that caused the patient's injury. The court strongly held that "A pharmaceutical manufacturer is not required to warn anybody other than prescribing physicians about the dangerous propensities of their prescription drugs and medical devices. Period." Several cases were cited by Justice Joseph R. Goodwin to support his ruling such as Carlin v Superior Court, 13 Cal. $4^{\text {th }} 1104$ (Cal.1996), in which the court held that the 'duty to warn runs to the physician and not to the patient'. In Brown v Superior Court, 44 Cal. 3d 1049 (Cal. 1988) the court held that 'It is well established that a manufacturer fulfills its duty to warn if it provides adequate warning to physicians.' In the case of Motus v Pfizer Inc 196 F. Supp 2d 984 (C.D.Cal 2001); Conte v Wyeth Inc, 168 Cal.App. $4^{\text {th }} 89$ (Ct. App. 2008); Girod (2007); Calabro (2003-2004); Tammy Muzichuck v Forest Laboratories Inc \& Forest Pharmaceuticals, Dist. Court, ND West Virginia 2014; In Re: Ethicon Inc, Dist. Court SD West Virginia 2014) the courts have arrived to the same conclusion.

There are various justifications for the rule of learned intermediary as set forth by several scholars. Among the main reasons mentioned by Calabro (2004) is the vast gap of knowledge between the patients and the expertise of physicians in the field of medical treatment. Physicians are in the best position to deliver information pertaining to the risks of medical products and to explain in lay terms the medical jargon, where it is difficult for patients to comprehend and understand the complexity and severity of a given warning. Reyes v. Wyeth Lab (498 F.2d 1264, 1276 (5 $5^{\text {th }}$ Cir.) (1974)) which has been cited numerous times by courts in deciding the application of LIR, summarized the manufacturer's duty to warn as follows:

[W] here prescription drugs are concerned, the manufacturer's duty to warn is limited to an obligation to advise the prescribing physician of any potential dangers that may result from the drug's use... Prescription drugs are likely to be complex medicines, esoteric in formula and varied in effect. As a medical expert, the prescribing physician can take into account the propensities of the drug, as well as the susceptibilities of his patients. His is the task of weighing the benefits of any medications against its potential dangers. The choice he makes is an informed one, an individualized medical judgment bottomed on knowledge of both patient and palliative.

Secondly, the fiduciary relationship between the physician and patient puts the physician in the best position to assess each patient's needs, the risks and benefits earned during the treatment (Jeffrey W. Kemp et al, 2007). Patients rely heavily on the physician's professional knowledge of medicine and any proposed treatment provided by physicians (R.Friedman, 2010). Manufacturers have no obligation to warn patients because based on this rule, a physician acts as an intermediary between users and producers of knowledge. Thus, having manufacturers warn patients directly interferes with the traditional doctor-patient relationship (Bordes, 2004). This rule shifts the burden on the physician to ensure that the risk warning regarding use of medical products is delivered adequately (Martin by Martin $v$ Ortho Pharmaceutical Corp. 661 N.E.2d 352 (III. 1996)).

Thirdly, it is impossible for manufacturers to communicate warnings and information about the pharmaceutical product to each patient as the real consumer is the physician, not the patient (Calabro, 2004; Hill, 2005). In the case of Hill $v$ Searle Labs (884 F2d 1064, 1070 98 th Cir. 1989), the court held that "it is virtually impossible in many cases for a manufacturer to directly warn each patient...the information regarding risks is often too technical for a patient to make a reasonable choice".

Courts however have articulated a number of rationales as exceptions to the LIR and the exceptions have gained virtually universal acceptance in prescribing pharmaceutical products such as mass immunization (Davis v Wyeth Lab Inc 399 F2d 121 (9th Cir.1968)), vaccination, contraceptive pills or prescribing medical devices such as contraceptive devices, IUD (Hill v Searle Labs 884 F2d 1064, 1070 98 $8^{\text {th }}$ Cir. 1989)). Courts claimed that in cases involving contraceptive pills, the physician plays a passive role in prescribing these types of medication as it has higher patient participation and in certain situations, patients demand a particular brand of contraceptive pill (MacDonald v Ortho Pharm.Corp. 475 N.E.2d 65 (Mass. 1985)). Courts find that the physician's role is relegated to a supporting role in the initial decisions of the patients (Odgers v Ortho Pharma. Corp. 609 F. Supp. 867,878 (E.D Mich. 1985)). The New Jersey Supreme Court shares the same findings as cases decided above in which the court found that 'when consumers are confronted by direct to consumer advertisement, they enter a physician's office with a preconceive notion about the oral contraceptive usage' (Perez v Wyeth Laboratory Inc. 734 A.2d 1245, 1260). Nagy (2001) argues that 'the physician faces a tainted relationship when dealing with patients and new relationships born from prescription drug advertisement which affects the proximate cause of prescribed based injury and hence these advertisements could negate the role of physicians.' The reason is the 
same for mass immunization as the physicians play little role in administering immunization to patients since it is not based on his decision.

Therefore, based on discussion above, it is essential to note that the defence have been widely accepted in the United States and the courts in commonwealth countries have also begun to consider it in ruling the cases involving failure to warn or defective labeling for pharmaceutical products. Hence, if this defence is invoked in Malaysia, the consequence would be grave to patients as their claim compensation can be denied based on decided cases as stated above.

\section{Application Of Learned Intermediary Rule In Malaysia}

Analysis above shows that in order for the manufacturer to rely on LIR, first the manufacturer must prove that the pharmaceutical products are prescribed products. Secondly, the physician is the learned intermediary between the manufacturer and patients. Thirdly, all information and warnings have been explained and notified to the physician via labels on the pharmaceutical products or representation from the pharmaceutical company. In order to investigate the application of LIR in Malaysia, it is best to first understand how prescribed pharmaceutical products are being distributed from manufacturers of medical products to patients. Therefore, this part attempts to identify the learned intermediary by studying the statutory duty of manufacturers of medical products under the Poison Act 1952 and Medicines (Advertisement and Sale) Act 1956. This method of analysis is adopted as per studies conducted by Ferguson (1992) in identifying the learned intermediary between manufacturers of medical products and patients in the United Kingdom by scrutinizing various statutes.

\subsection{Understanding the Flow of Sale and Supply of Prescribed Pharmaceutical Products under the Poison Act 1952.}

In identifying a learned intermediary for pharmaceutical products, the Malaysian Poisons Act 1952 (PA 1952) is an Act that controls the importation, possession, production, compounding, storage, transportation, sale and use of toxic substances that have been listed under the first column of Table II. Section 7 (3) of the PA 1952 clearly forbids the sale and supply of drugs, medicines containing poisons (which will be referred to as 'poisons') to outpatients by any officer or person who works in a hospital, infirmary, dispensaries, clinics, nursing homes, animal hospitals operated by the Malaysian Government, State Government, local authorities and others for the purpose of treatment, use in wards, operating rooms or dental treatment unless the sale and supply is made and executed in accordance with prescribed regulations (Poison Regulations 1952).

This means that every medicine that contains poison listed under Table II which is supplied or sold by the parties mentioned above must observe and comply with the regulations. It is an offense if any person is found to have medicines and intends to sell without a valid license to sell or supply it. The law demands that in order for wholesalers, retailers, registered medical and dental practitioners, government departments, hospitals or institutions related to scientific research for the purpose of analysis or research or registered pharmacists to sell or distribute such medicine to members of the general public, it shall be mandatory to hold a valid license (sections 13, 15, 16 and 18 PA 1952). The relevant sections pertaining to prohibitions of the sale and supply of poisons are set out in Table 1 below:

Table 1: Prohibition to Sell and Supply Poison under the Poison Act 1952

\begin{tabular}{|c|c|}
\hline Sections & Content \\
\hline $\begin{array}{l}\text { Section } 20 \\
\text { Group A Poisons }\end{array}$ & $\begin{array}{l}\text { Group A Poison shall not be sold or supplied by wholesale or retail except: } \\
\text { (a) By a licensed wholesaler to a licensed pharmacist or to another licensed wholesaler; or } \\
\text { (b) By a licensed wholesaler to be immediately exported to a purchaser outside Malaysia }\end{array}$ \\
\hline $\begin{array}{l}\text { Section } 21 \\
\text { Group B Poisons }\end{array}$ & $\begin{array}{l}\text { (1) Group B Poison shall not be sold or supplied by retail to any person except: } \\
\text { (a) ....authorized under section 20; } \\
\text { (b) By a registered medical practitioner, registered dentist...; } \\
\text { (c) By a licensed pharmacist, as a dispensed medicine and in accordance with a prescription prescribed } \\
\text { by a registered medical practitioner, registered dentist... }\end{array}$ \\
\hline $\begin{array}{l}\text { Section } 22 \\
\text { Group C Poison }\end{array}$ & $\begin{array}{l}\text { Group C Poison shall not be sold or supplied by retail to any person except: } \\
\text { (a) .....authorized by section } 21 \text { or } \\
\text { (b) As a dispensed medicine or an ingredient in a dispensed medicine. }\end{array}$ \\
\hline $\begin{array}{l}\text { Section } 23 \\
\text { Group D Poisons }\end{array}$ & $\begin{array}{l}\text { 1) Group D Poison shall not be sold or supplied by retail to any person except: } \\
\text { (a) ....authorized of section } 22 \\
\text { (b) By a licensed pharmacist to a person known personally to such pharmacist or introduced to the } \\
\text { pharmacist personally ... }\end{array}$ \\
\hline
\end{tabular}

It is apparent from Table 1 that the flow of sale and distribution of poison is from one licensed party to the next and the 
only way for patients to receive or be supplied with such poisons are via registered physician, registered dentist or licensed pharmacists or as dispensed medicine. This finding is in agreement with studies conducted by Ferguson (1992) where she identify the learned intermediary by scrutinizing the United Kingdom's Medicine Act 1968 and the Medicines (Data Sheet) Regulations 1972 No. 2706. These legislations compel the pharmaceutical manufacturers to convey all information pertaining to the product in their data sheet to the medical practitioner. It is in accordance with the requirement under section 96 Medicine Act 1968, which provides in subsection (1) that 'no advertisement relating to medicinal products or a particular description, other than a data sheet, shall be sent or delivered to a practitioner'. The data sheet that is related to the medicinal products has been sent or delivered to him not more than fifteen months before the date on which the advertisement is sent or delivery of representation is made'(section 96 (3)(a) Medicine Act 1968). This finding supports Ferguson's contention that medicines shall be brought to the knowledge of a medical practitioner, a learned intermediary, fifteen months before supplying it to its treating patient, giving ample time to study the product. Section 96 (5)(a) and (b) under the Medicine Act 1968 sets out the punishment of imprisonment for not more than two years or a fine not exceeding GBP400 or both for failure to adhere to the provisions above.

Based on the above analysis, understanding the flow of pharmaceutical products by analyzing the provisions under PA 1952 has shown that pharmaceutical products are channeled through a learned intermediary such as registered physicians. This finding supports the justification of the defense of LIR by Kemp et al (2007) whereby he maintains that the physician is in the best position to convey warnings and information to the end-user; patients.

In Australia, Justice Kiefel in the case of Carey-Hazell v. Getz Bros. \& Co. (Aust) Pty \& Ors considered briefly the relevant issue of duty to warn by the manufacturer of a heart valve. It was found that the patient suffered from various symptoms and complications due to the heart valve, which was implanted in his heart. The manufacturer invoked this defense and submitted authorities for consideration such as cases decided in U.S. courts. One such case was Sterling Drug Inc.v Cornish, which made use of the term LIR. LIR was to describe the relationship between a physician, the patient and the pharmaceutical manufacturer, where the physician is considered as an intermediary between the patient and pharmaceutical manufacturers.

The cases of Phelps $v$ Sherwood Medical Industries (7th Cir 1987) 836 F.2d 296) involved the manufacturers of heart catheters and Brooks. v Medtronic. Inc. (4th Cir 1984) 750 F.2d 1227 involved defective pacemakers. The court took into account the decision of the Court of Australia that adopted this defense in the case of H.v Royal Alexandra Hospital for Children ((1990) Aust Torts Reports 81-000), in which the court held that the duty of care of manufacturers is only adequately discharged once they warn the medical practitioner. The court did not elaborate this defense as medical practitioners knew the risks and warnings of these risks had also been presented to the patient. Therefore the patient's claim was rejected, hence no compensation was awarded.

As a result of decided cases and arguments by Ferguson, it is very likely that the LIR is a valid defense and can be invoked by pharmaceutical manufacturers. The grave consequence of this matter is that it may leave patients uncompensated for the injuries they suffer.

\subsection{Advertisement of Medical Products under Medicines (Advertisement and Sale) Act 1956}

Further evidence that the defense may be very likely accepted as a defense in Malaysia is by studying the Medicines (Advertisement and Sale) Act 1956 (MASA 1956). This Act indicates strong evidence of limiting the conduct of pharmaceutical manufacturers to advertise their products in which under the provision of section 3 , any related advertising drugs for treating specific ailments are prohibited as in Table 2 below:

Table 2: Provisions prohibiting advertising under MASA 1956

Sections Contents

(1) no person shall take any part in the publication of any advertisement referring to any article, or articles of any description, in terms which are calculated to lead to the use of that article or articles of that description as a

Section $3 \quad$ medicine, an appliance or a remedy for the purpose of:

Prohibition of $\quad$ (a) prevention or treatment of the disease and conditions of human beings as specified in the Schedule;

advertisements relating to (b) practicing contraception among human beings;

certain disease $\quad$ (c) improving the condition or functioning of the human kidney or heart, or improving the sexual function or sexual performance of human beings;

(d) diagnosis of a disease as specified in the schedule:

Section $4 \quad$ No person shall take any part in the publication of any advertisement referring to any article, or articles of any

Prohibition of advertisement description, in terms which are calculated to lead to the use of that article or articles of that description for procuring the relating to abortion miscarriage of women

Section $4 B$

Advertisement of medicines

to be approved

(1) No person shall take part in the publication of any advertisement referring to any article....o that description as a medicine an appliance or a remedy for the purpose of treatment or prevention of diseases or conditions specified in section 3(1) unless such advertisement has been approved by the Medicine Advertisement Board. 
Failure to comply with the above provisions can amount to an offense under section 5; first-time offenders are punishable by a fine not exceeding RM3000 or imprisonment not exceeding one year or both. The result of this study indicates that any form of advertising including notices, reports, comments, pamphlets, labels, wrappers or other documents and any announcements or any other method of transmitting sound and light related to drugs is prohibited and cannot be made to the patient. These drugs can only be advertised for the purpose of knowledge for certain groups of people such as registered medical practitioners, registered dental practitioners, nurses, pharmacists, chemists, wholesalers and vendors who are licensed under Poison Act 1952, or someone who is training to be a medical practitioner, dental practitioner, nurse, pharmacist and registered chemist.

This further strengthens the authors' arguments that any pharmaceutical products for the treatment of disease shall be conveyed via intermediaries and cannot be advertised to patients; advertising is only allowed to convey specific knowledge to non-users only. The rationale behind this supposition is that only those with backgrounds in medical studies may be able to appreciate and understand the nature of a pharmaceutical product and evaluate which patients are suitable for treatment (Calabro, 2004). The analysis above produced results which corroborated the findings of Friedman (2010), which state that:

...the pharmaceutical manufacturer's duty to warn the doctor alone stems from the doctor's professional knowledge of medicine and the doctor's unique position as a liaison between the pharmaceutical manufacturer and the patient. From a legal perspective, the doctor's unique position makes her the party responsible for determining the patient's use of the drug.

If however, there are indications that prescribed pharmaceutical manufacturers are involved in aggressive campaigning or direct-to-consumer advertisement, liability may be imposed. Nagy (2001) states that the advertisement overrides the learned intermediary defense based on the decision by the Massachusetts District Court in the case of Garside v Osco Drug, Inc (764 F. Supp.208, 212 (Mass. Dist. Ct 1991). The court held that "when manufacturers advertise directly to consumers, they "bypass" the traditional doctor/patient relationship and lessen the role of the learned intermediary." This indicates that before the court accepts the defense of learned intermediary rule, the court would examine the extent of accessibility to such advertisements, especially when they are posted on the internet, which patients have easy and direct access to.

One question that needs to be asked, however, is whether leaflets provided by pharmaceutical manufacturers are intervening between the relationship of physician and patient? The Malaysian Ministry of Health has conducted an active campaign called 'Know Your Medicine' via the official website of The National Pharmaceutical Control Bureau (NPCB) (http://portal.bpfk.gov.my/). The campaign is in conjunction with the Consumers Association of Malaysia (FOMCA) which was launched on 29th June 2007. Under this campaign, the consumers, especially patients, are able to search for information about registered prescription and non-prescription medicines via the Consumer Medication Information Leaflets provided online. According to the campaign, 'the leaflets are targeted for the consumer, containing information on how the drug works, how to use it, what precautions to take, use of the drug during pregnancy, what to do if you miss a dose, and possible side effects or interactions.'

Is this direct-to-consumer advertisement in which the language used is targeted at patients and made easier for patients to understand? According to the author's research, the leaflets are prepared and endorsed by pharmaceutical manufacturers, which also contain warnings of risks of adverse reaction. Given the nature of the information, it clearly shows a direct contact with the patients in which the manufacturer cannot seek the defense of LIR as it tends to 'bypass the traditional doctor/patient relationship and lessen the role of the learned intermediary' (Garside v Osco Drug, Inc (764 F. Supp.208, 212 (Mass. Dist. Ct 1991). However, it was decided in the negative in the case of Jane Polley v. Ciba-Giegy Corporation 1987 U.S. Dist. LEXIS 3431 that involved the issue of admissibility of 'patient brochures' as evidence provided by the manufacturer. Justice $\mathrm{H}$. Russel Holland held:

"...there is a possibility that the patient brochure evidence may be admissible on the issue of whether the manufacturer has breached its duty to warn physicians. Such patient brochure evidence is relevant to issues relating to duty to warn the learned intermediary."

The court would only consider the patient brochures as evidence to determine whether the manufacturer had warned the physicians of complications and adverse reactions. Hence, if there was inconclusive evidence as to whether the manufacturer had warned the physician, then the brochure would be admissible. The court accepted the manufacturer's defense as the manufacturer's duty was only to provide information to the physician and had no duty to inform patients directly or to provide patients with brochures.

The authors agree with the decision of the court because in the leaflets provided by the pharmaceutical manufacturer, there were still several medical jargons that patients would have been unable to understand. It is argued that the duty to warn still lay upon the physicians as exemption clauses such as 'Please contact your doctor or pharmacist 
if you have any further questions about your medicine' are printed in the leaflets. The prescription of pharmaceutical products still requires physicians to evaluate whether the patient is a suitable candidate for the medicine. This supports the decision in Perez v Wyeth Laboratory Inc. 734 A.2d 1245, 1260, where Wyeth Laboratories began aggressive marketing of the prescription drug Norplant. In determining whether the LIR applied, the court held that even if the advertisement was directed to patients, it does not relegate the physician's role as the physician 'still must weigh the risks and benefits associated with the drugs for patients prior to prescribing the drug'. Hence, the LIR applied in this case.

\section{Conclusion}

In this article, the aim is to determine whether Malaysian courts would accept the defense of LIR. There seems to be valid justification for shifting duty to warn to physicians. However, although extensive research has been carried out pertaining to LIR, to date, far too little attention has been paid to the LIR in Malaysia whilst the courts in the United Kingdom, Australia and Canada have already considered this defense. The result of this article has shown that based on the provisions set out in the relevant statutes above, the flow of sale and supply of pharmaceutical products must be channeled through a registered physician, a learned intermediary. It is argued that even though there are no case reports pertaining to duty to warn for pharmaceutical products in Malaysia, based on the analysis on the Poison Act 1952 and Medicines (Advertisement and Sale) Act 1956, it is very likely that the defense of LIR would be invoked by the manufacturers as decided in numerous cases in the United States. Besides examining the legislations to identify the learned intermediary between the pharmaceutical manufacturer and patients, several studies have chosen the method of case study in order to examine the approach taken by courts in deciding issues pertaining to duty to warn and the defense of LIR. Although these cases do not have any binding effect in Malaysian courts, it can be clearly seen as shown above that this defense has already been considered in Australia. It is therefore reasonably foreseeable that Malaysia will follow and from the above analysis, this defense is a defense with merit. It is the argument of the authors that the probability for such defense to be invoked by prescribed pharmaceutical manufacturers and accepted in the courts of law in Malaysia is high due to the fact that there are decided cases in Commonwealth countries where the pharmaceutical manufacturers managed to escape liability and countless cases in the United States, the birthplace of LIR, which have adopted the same.

Based on the above analysis, this article has given an account of and the reasons for the widespread use of the LIR defense. An implication of this is that patients may not be able to recover any compensation from pharmaceutical manufacturers and that considerably more work will need to be done in near future to examine how to assist patients in search for justice.

\section{References}

Barney, J. 2003-2004. Dancing Towards Disaster or the Race of Rationality: The Demise of the Learned Intermediary Standard and the Pharmacists' Duty to Warn, 39 Gonz. L. Rev. 399.

Bordes, O.A. 2003-2004. The Learned Intermediary Doctrine and Direct-to-Consumer Advertising: Should the Pharmaceutical Manufacturer Be Shielded From Liability?, 81, U. Det. Mercy L.Rev. 267.

Calabro, S. 2003-2004. Breaking The Shield Of The Learned Intermediary Doctrine: Placing The Blame Where It Belongs, 25 Cardozo L.Rev. 2241.

Casey, S.A.1993. Laying An Old Doctrine to Rest: Challenging The Wisdom of the Learned Intermediary Doctrine, 19 Wm. Mitchell L.Rev. 931.

Chatfield II, L.C. 1993-1994. Medical Implant Litigation and Failure to Warn: A New Extension for the Learned Intermediary Rule?, 82 Ky. L.J 575.

Dillard, H.C et al. 1955. Product Liability: Directions for Use and the Duty to Warn, 41 Va. L.Rev. 145.

Ferguson, P.R.1992. Liability for Phamarceutical Products: a Critique of the "Learned Intermediary' Rule, 12 Oxford J.Legal Stud. 59.

Friedman, R.J. 2009-2010. Take Two of These and Sue Me In The Morning: Efficacy of the Learned Intermediary Doctrine in Prescription Drug Failure To Warn Cases, 22 St. Thomas L.Rev. 278.

Girod, J. 2007. The Learned Intermediary Doctrine: An Efficient Protection for Patients, Past and Present, 40 Ind. L. Rev. 397.

Hill, J.C. 2005. The Learned Intermediary Doctrine and Beyond, Exploring Direct-to-Consumer Drug Advertising Liability in The New Millennium, 72 Def. Counsel J. 362.

Kemp, J.W et al. 2007. The Bulk Supplier, Sophisticated User, and Learned Intermediary Doctrines since the Adoption of the Restatement (Third) of Torts, 26 Rev. Litig. 927

Marshall, L.K. 2000-2001. Keeping The Duty To Warn Patients Of The Risks And Side Effects Of Mass-Marketed Prescription Drugs Where It Belongs: With The Medical Practitioner, 26 U.Dayton L.Rev. 95.

Nagy, J.E. 2000-2001. The Learned Intermediary Doctrine: Striking A Balance Between Liability For Manufacturers And Medical practitioner In The Changing Arenas Of Managed Healthcare, The Practice Of Medicine And Direct-To-Consumer Pharmaceutical Promotion Of Oral Contraceptive, 5 J. Med. \& L. 53. 